\title{
Lipids and lipoproteins in Friedreich's ataxia
}

\author{
J. L. WALKER, S. CHAMBERLAIN, AND N. ROBINSON \\ From the Friedreich's Ataxia Research Unit, London Hospital Medical College, London.
}

SUMMARY Friedreich's ataxia is an autosomal recessively inherited disease affecting the nervous system with a high incidence of heart involvement. Abnormalities of lipid metabolism are known to be associated with several progressive ataxic conditions. In this study of 46 Friedreich's ataxia patients, serum lipids, fatty acids and lipoproteins were assayed and compared with some earlier findings on Friedreich's ataxia and related disorders. Abnormalities of low and high density lipoproteins suggestive of a major defect have been reported; in the present study the level and chemical composition of high density lipoprotein has been assessed in 20 Friedreich's ataxia patients but previous abnormalities could not be substantiated. Lipid compositional analysis of Friedreich's ataxia central nervous tissue and heart, which has not been previously reported, did not markedly differ from control tissue.

Friedreich's ataxia is one of the more common hereditary diseases of the nervous system ${ }^{1}$ which may be defined by restrictive criteria as outlined by Geoffroy et al. ${ }^{2}$

Certain diseases having neurological symptoms are known to be associated with lipid metabolism and transport errors. A major group of inherited metabolic disorders that are characterised by profound deleterious effects on the central nervous system are distinguished by the accumulation of excessive quantities of lipids in various organs and tissues throughout the body. ${ }^{3}$

A progressive demyelinating disorder ${ }^{4}$ and a kindred with signs and symptoms of a spinocerebellar degeneration similar to Friedreich's ataxia ${ }^{5}$ have both been reported to exhibit low levels of low density lipoprotein (LDL). Further, the cardiac disturbances and ataxia present in Friedreich's ataxia are also found in abetalipoproteinaemia, ${ }^{6}$ a condition in which little or no LDL is found in serum. Recently, Wastiaux et $a l^{7}$ and Huang et $a l^{8}$ have reported decreased levels of low and high density lipoproteins in Friedreich's ataxia and other ataxic conditions and major differences in the composition of high density lipoproteins (HDL).

Fatty acid abnormalities have been reported in other ataxic conditions. Refsum's disease which

\footnotetext{
Address for reprint requests: Dr $\mathbf{N}$ Robinson, Friedreich's Ataxia Research Unit, London Hospital Medical College, Turner Street, London E1 2AD.

Accepted October 1979
}

is an hereditary form of ataxia and polyneuritis, is associated with an unusually large amount of a 20-carbon methylated fatty acid in plasma and tissue. ${ }^{9}$ Adrenoleucodystrophy, an X-linked hereditary neurological disorder, shows abnormal very long chain fatty acids, principally in the cholesterol esters of brain, suprarenal glands and serum. $^{10}$

Nervous tissue lipids are important both as structural constituents and as participants in the functional activity of the central nervous system. Identification of abnormally stored lipids in some genetically determined metabolic disorders has introduced the possibility that an abnormality in the chemistry or metabolism of one of the unique nervous system lipids may be involved in Friedreich's ataxia. Previously Robinson ${ }^{11}$ has shown that the affected regions of the spinal cord in Friedreich's ataxia do show lipid loss from proteolipids. The three major categories of brain lipids have been investigated in this study.

In view of the association of progressive ataxic disease and abnormalities in lipids and lipoproteins, the present study was undertaken to investigate some of these components and ascertain their possible involvement in Friedreich's ataxia.

\section{Methods}

Forty-six patients were used in the study, all of whom had been seen by a neurologist within the last 2 years and the diagnosis confirmed. All 
Table 1 Friedreich's ataxia patients (46 cases)

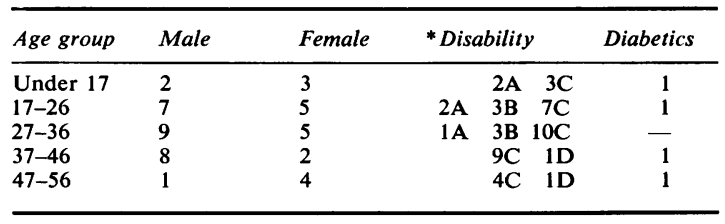

*A Walking without aid

B Walking only with substantial aid

C Confined to a wheelchair

D Bedridden

patients met the essential criteria of Geoffroy $e t$ $a l^{2}$ : ataxia began before the end of puberty and was unrelentingly progressive, the patients exhibited dysarthria, muscle weakness, a decrease of position or vibratory sense and deep tendon areflexia in the lower limbs. Recessive inheritance was suggested in all cases. Table 1 shows the age range and disabilities of the patients involved in the study.

Neurological controls had various diagnoses, mainly of multiple sclerosis (12), muscular dystrophy (3), spasticity (3), Parkinsonism (2), and quadraplegia (2). Normal control blood was obtained from healthy volunteers. As far as possible Friedreich's ataxia patients and controls were matched for age, sex, physical activity and body weight.

\section{EXPERIMENTAL PROCEDURES}

Venous blood was obtained after an overnight fast. The blood was allowed to clot and after centrifugation the serum removed. Serum was then either used immediately or frozen at $-20^{\circ} \mathrm{C}$ until analysis within one month of collection. Controls of similar age and disability were used throughout the study, unless normal ranges were well established.

(a) Total serum cholesterol in 20 Friedreich's ataxia patients was extracted into isopropanol and measured on a Technicon AA1 system by the method of Zlatkis $e t a l^{12}$ and the proportion of free to esterified cholesterol was estimated using the Boehringer Mannheim Test Combination. Total triglyceride was measured in 20 Friedreich's ataxia patients according to Eggstein et $a{ }^{13}$

(b) For the measurement of the plasma fatty acid profile, the total lipid was extracted according to Folch et al $^{14}$ as modified by Danon et al. ${ }^{15}$ Cholesterol esters, triglycerides and phospholipids were separated and their methylated fatty acids prepared by incubation with $14 \%$ boron trifluoride in methanol at $65^{\circ} \mathrm{C}$ for 3 hours and subsequently estimated on a Pye Unicam Model
104 Gas Liquid Chromatograph; 10 Friedreich's ataxia and 10 control patients were assessed in each lipid category.

(c) Low density lipoprotein levels (LDL) were measured by radial immunodiffusion ${ }^{16}$ in sera of 25 Friedreich's ataxia and 17 control patients, using Behring Werke M-partigen plates, (purported to have negligible non specific activity) and human standard low density lipoprotein serum. Agarose gel electrophoresis was used to estimate the proportion of LDL and HDL in whole serum ${ }^{17}$ in 10 Friedreich's ataxia and seven control patients. Using this proportional method, pooled serum from 20 normal controls was used to produce a standard HDL serum. The high density lipoprotein (HDL) level was measured by rocket immunoelectrophoresis essentially as described by Laurell. ${ }^{18}$ Twenty-four Friedreich's ataxia patients, four neurological controls and 20 normal controls were tested. Human high density lipoprotein antisera was obtained from Behring Werke having a titre of $0.2 \mathrm{U} / \mathrm{ml}$.

(d) The dual precipitation method of Demacker et al $^{19}$ was used to prepare HDL for measurement of cholesterol after extraction with isopropanol ${ }^{12}$ and phospholipids ${ }^{20}$ in 20 Friedreich's ataxia patients, 10 neurological and 20 normal controls. Phosphatidylcholine (Sigma Chem. Co.) was the reference standard in the latter method.

(e) Ultracentrifugation techniques were based on those of Lindgren and Nichols. ${ }^{21}$ Three $\mathrm{ml}$ of serum was raised to a density of 1.063 with $4 \mathrm{ml}$ of aqueous $\mathrm{NaBr}$ and spun for 16 hours at $86000 \mathrm{~g}$ and $14^{\circ} \mathrm{C}$ in an MSE Superspeed 65 with Rotor 59113 . The top $1.5 \mathrm{ml}$ supernatant fluid was removed and discarded. Two successive spins were then performed for 29 hours at $143000 \mathrm{~g}$ and $14^{\circ} \mathrm{C}$ raising the solution density to 1.125 and then 1.210 with solid $\mathrm{NaBr}$. The top $1 \mathrm{ml}$ from each spin containing HDL2 and HDL3 respectively was removed by careful pipetting. The protein component was measured by the methods of Lowry et $a l^{22}$ and Pesce and Strande. ${ }^{23}$ Total and free cholesterol were estimated using the Boehringer Mannheim Test Combinations and phospholipids as in (d). Sodium dodecyl sulphate (SDS) polyacrylamide gel electrophoresis was carried out for 4 to 5 hours on HDL2 and HDL3 after exhaustive dialysis of the lipoproteins in a dialysate of EDTA $(0.05 \%)$ and $\mathrm{NaCl}$ $(0.15 \mathrm{mM})$ adjusted to $\mathrm{pH} 7.0$ with $\mathrm{NaOH}^{24}$ using a $7.5 \%$ gel with a phosphate buffer system. Isoelectricfocusing was performed with the LKB ampholine system, using narrow range $\mathrm{pH} 4-6.5$ plates and electrofocusing for 3 to 3.5 hours at 25 watts. $^{25}$ 
(f) The basic analytical scheme of Suzuki ${ }^{26}$ employing thin layer chromatographic techniques, was used to examine the lipids of the grey and white cerebrum, cerebellum, spinal cord and heart. Tissue from two Friedreich's ataxia patients and one control (cancer of the ovary) obtained within 6 hours of death was frozen immediately under liquid nitrogen and subsequently stored at $-20^{\circ} \mathrm{C}$ until use. The three major categories of nervous tissue lipids investigated by this method were cholesterol, sphingolipids and glycerophosphates.

\section{Results}

(a) The total serum cholesterol, triglycerides and ratio of esterified to free cholesterol were within acceptable limits of the hospital normal ranges and compared well with other published values. ${ }^{28}$ Two patients were on the upper limit of the normal cholesterol range, while one patient was above the normal triglyceride range (table 2).

(b) The fatty acid profiles in total serum, phospholipids, triglycerides and cholesterol esters (table 3) showed no significant abnormalities. The percentage of the major fatty acids were normal compared to controls and no abnormal
Table 2 Serum cholesterol and triglycerides $($ mean $\pm S D)$

\begin{tabular}{lrll}
\hline Lipid & \multicolumn{2}{l}{ Friedreich's } & Normal range \\
\hline Total cholesterol m mol/1 & $5.3 \pm 1.5$ & $(20)^{*}$ & $3.6-7.0$ \\
Total triglycerides m mol/1 & $1.2 \pm 0.5$ & $(20)^{*}$ & $0.3^{*} 1.8$ \\
Esterified cholesterol \% & $71.2 \pm 6.6$ & $(10)^{*}$ & $65^{*} 75$ \\
Free cholesterol \% & $28.8 \pm 6.6$ & $(10)^{*}$ & $25-35$ \\
\hline
\end{tabular}

()* Number of patients

fatty acids were observed. Slightly low values of linoleic and arachidonic acids were initially observed in the Friedreich's ataxia patients but comparison with controls of equal age and disability revealed no differences.

(c) Serum lipoprotein levels in the Friedreich's ataxia patients and controls are shown in table 4 . Although there are only a few people in each age and sex range, no decreased levels of LDL were found, but slightly increased LDL levels compared to the normal American adult population of Lindgren et $a^{29}$ were seen in six Friedreich's ataxia patients out of the 29 studied and in three of the 17 controls. HDL values were normal in 13 of the 20 Friedreich's ataxia patients and 15 of the 20 controls, but increased levels were found in five Friedreich's ataxia patients and

Table 3 Fatty acid profile of serum lipids

\begin{tabular}{|c|c|c|c|c|c|c|c|c|}
\hline \multirow[t]{2}{*}{ Fatty acid } & \multicolumn{2}{|c|}{ Serum lipids $\%$} & \multicolumn{2}{|c|}{ Phospholipids \% } & \multicolumn{2}{|c|}{ Triglycerides $\%$} & \multicolumn{2}{|c|}{ Cholesterol esters \% } \\
\hline & F. ataxia* & Controls $\ddagger$ & $\overline{F . \text { ataxia }}$ & Controls $\ddagger$ & F.ataxia* & Controls $\ddagger$ & F.ataxia* & Controls $\ddagger$ \\
\hline $14: 0$ & $1.8 \pm 0.5$ & $1.7 \pm 0.6$ & $0.8 \pm 0.4$ & $1.1 \pm 0.3$ & $2.2 \pm 0.8$ & $2.3 \pm 0.7$ & $1.3 \pm 0.5$ & $1.5 \pm 0.5$ \\
\hline $16: 0$ & $28.0 \pm 3.7$ & $27.4 \pm 6.8$ & $30.1 \pm 3.4$ & $30.1 \pm 2.8$ & $28.1 \pm 2.0$ & $29.7 \pm 3.7$ & $12.3 \pm 3.7$ & $11.9 \pm 1.8$ \\
\hline $16: 1$ & $3.9 \pm 1.5$ & $3.7 \pm 1.7$ & $1.2 \pm 0.8$ & $2.2 \pm 1.0$ & $5.6 \pm 1.5$ & $6.4 \pm 1.2$ & $5.5 \pm 2.6$ & $7.3 \pm 2.4$ \\
\hline $18: 0$ & $8.9 \pm 2.3$ & $8.1 \pm 2.6$ & $17.2 \pm 2.3$ & $17.1 \pm 3.1$ & $5.2 \pm 1.1$ & $4.9 \pm 1.3$ & $2.4 \pm 1.0$ & $2.1 \pm 1.7$ \\
\hline $18: 1$ & $26.5 \pm 3.9$ & $27.5 \pm 3.5$ & $17.8 \pm 4.2$ & $16.8 \pm 3.9$ & $45.6 \pm 3.8$ & $46.1 \pm 4.0$ & $25.1 \pm 4.0$ & $26.2 \pm 3.5$ \\
\hline $18: 2$ & $23.3 \pm 3.2$ & $23.8 \pm 4.9$ & $25.7 \pm 3.6$ & $25.1 \pm 3.1$ & $11.5 \pm 3.7$ & $9.5 \pm 3.7$ & $47.6 \pm 6.8$ & $45.2 \pm 5.9$ \\
\hline $20: 4$ & $7.6 \pm 3.2$ & $7.8 \pm 2.1$ & $6.9 \pm 2.3$ & $7.1 \pm 2.0$ & $1.8 \pm 1.5$ & $1.3 \pm 2.1$ & $5.5 \pm 1.5$ & $5.9 \pm 2.1$ \\
\hline
\end{tabular}

* Means of 10 Friedreich's ataxia patients \pm SD

$\mp$ Means of 10 controls \pm SD

Table 4 Low density and high density lipoprotein levels measured immunologically (mean $\mathrm{mg} / 100 \mathrm{ml} \pm S D$ )

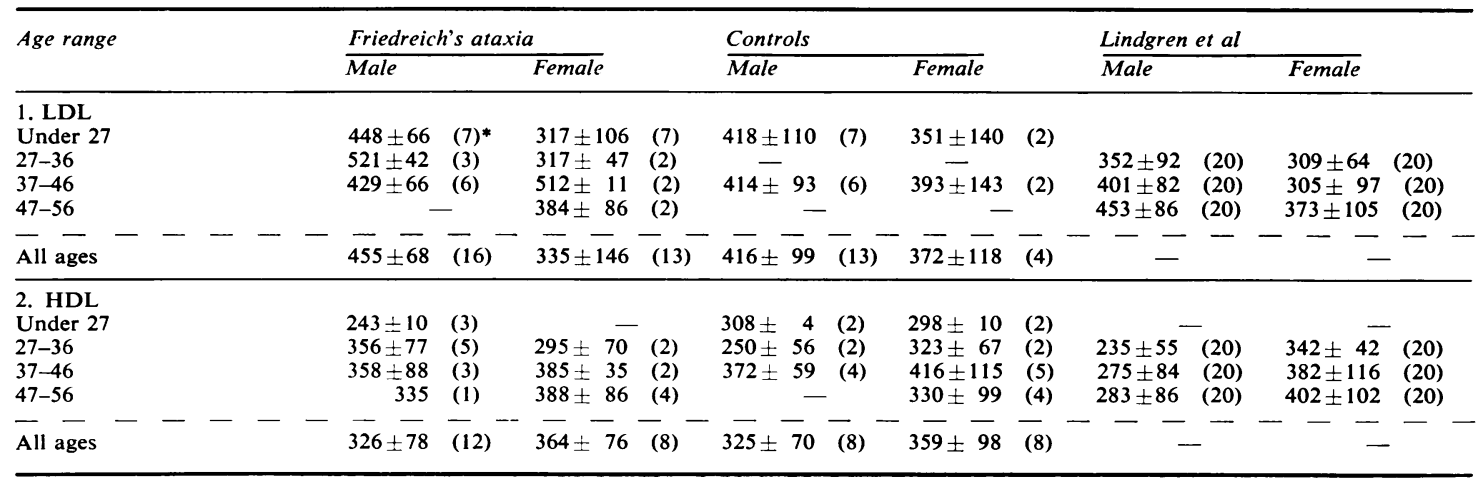

()* Number of patients. 
Table 5 High density lipoprotein composition (mean $\mathrm{mg} / 100 \mathrm{ml} \pm S D$ )

\begin{tabular}{|c|c|c|c|c|}
\hline \multirow[b]{2}{*}{$\begin{array}{l}\text { Protein } \dagger \\
\text { Protein } \ddagger \\
\text { Phospholipids \& } \\
\text { Phospholipids \| } \\
\text { Total cholesterol } ~ \\
\text { Total cholesterol P }\end{array}$} & \multicolumn{2}{|c|}{ Friedreich's ataxia } & \multicolumn{2}{|l|}{ Controls } \\
\hline & $\begin{array}{r}166.2 \pm 32.5 \\
178.5 \pm 32.4 \\
93.8 \pm 30.7 \\
98.5 \pm 16.7 \\
51.8 \pm 16.9 \\
46.6 \pm 8.2\end{array}$ & $\begin{array}{l}(20)^{*} \\
(10) \\
(20) \\
(10) \\
(20) \\
(10)\end{array}$ & $\begin{array}{r}174.9 \pm 35.4 \\
186.2 \pm 31.2 \\
89.8 \pm 37.8 \\
108.2 \pm 16.4 \\
57.7 \pm 26.1 \\
45.8 \pm 11.4\end{array}$ & $\begin{array}{l}(20) \\
(10) \\
(30) \\
(10) \\
(30) \\
(10)\end{array}$ \\
\hline $\begin{array}{c}\text { 0 Number of patients } \\
\text { † Ultracentrifugation } \\
\text { † Ultracentrifugation } \\
\text { \& Dual Precipitation } \\
\text { I| Ultracentrifugation } \\
\text { I Dual Precipitation } \\
\text { P Ultracentrifugation }\end{array}$ & \multicolumn{4}{|c|}{$\begin{array}{l}\text { Pesce and Strande (1973) } \\
\text { Lowry et al }(1951) \\
\text { Raheja et al }(1973) \\
\text { Raheja et al }(1973) \\
\text { Zlatkis et al (1953) } \\
\text { Boehringer Test Combination }\end{array}$} \\
\hline
\end{tabular}

four controls, while slightly low levels were found in two Friedreich's ataxia patients and one control. The proportion of HDL to LDL in 10 Friedreich's ataxia patients was $38.0 \%$ HDL to $62.0 \%$ LDL with a standard deviation of \pm 5.6 while in the seven controls the proportion was $34.5 \%$ HDL to $65.5 \%$ LDL with a standard deviation of \pm 4.0 . Normal values quoted for this method are $33.0 \%$ HDL to $67.0 \%$ LDL with an approximate standard deviation of 5\%. Both Friedreich's ataxia and control values fell within this range.

(d, e) Analysis of the serum HDL composition assessed using both the dual precipitation and the ultracentrifugation method is shown in table 5. Values obtained by ultracentrifugation were estimated by summation of the invidual components of HDL2 and HDL3. The percentage composition of the major components of total HDL, HDL2, and HDL 3 (excluding triglycerides) are shown in table 6 . The protein levels measured by the two methods varied but no significant differences were seen between the two groups.

Good correlation was found between the HDL cholesterol and the phospholipid measurement by dual precipitation and ultracentrifugation, with slightly increased results for phospholipids and decreased results for cholesterol by the latter method. The Friedreich's ataxia and control phospholipid and cholesterol values did not significantly differ, nor did the percentage composition of total HDL, HDL2 or HDL3.

SDS acrylamide gel electrophoresis of HDL2 and HDL3 showed two major bands which appear to correspond to Apoprotein A1 and Apoprotein A11 as described by Foreman et $a l^{30}$ and Eder and Roheim. ${ }^{31}$ In HDL3 three additional minor tands were consistently found in 10 Friedreich's ataxia and 10 control samples. Isoelectricfocusing revealed many bands, but no differences in banding could be seen between the Friedreich's ataxia and control gels.

(f) The total lipid analysis of the cerebrum. cerebellum, spinal cord and heart muscle showed no marked differences in position or intensity of banding of cholesterol, cerebroside, sulphatide, sphingomyelin or the choline, ethanolamine and serine phospholipids. The polyphosphoinositides were not extracted.

\section{Discussion}

Familial ataxia is known to occur in a variety of inborn errors of metabolism. Intermittent ataxia is seen in several specific aminoacidurias such as Hartnup disease ${ }^{32}$ and in certain defects of carbohydrate metabolism, for example, pyruvate dehydrogenase deficiency. ${ }^{33}$

Progressive unrelenting ataxia is more common in lipid metabolic disorders, such as phytanic acid storage disease ${ }^{9}$ and abetalipoproteinemia. ${ }^{6}$ Friedreich's ataxia is a progressive unrelenting ataxia and it is therefore possible that it is a lipid disorder.

Table 6 Percentage composition of total $H D L, H D L 2$ and $H D L 3$

\begin{tabular}{|c|c|c|c|c|c|c|}
\hline & \multicolumn{2}{|c|}{ Total $H D L \%$} & \multicolumn{2}{|l|}{$H D L 2$} & \multicolumn{2}{|l|}{ HDL3 } \\
\hline & $\overline{F . \text { ataxia }}$ & Control & $\overline{F . a t a x i a} \dagger$ & Control§ & $\overline{F . \text { ataxai }}$ & Control§ \\
\hline $\begin{array}{l}\text { Protein } 1 \\
\text { Phospholipid } \\
\text { Total cholesterol } \\
\text { Free cholesterol } 6\end{array}$ & $\begin{array}{c}52.2 \\
29.6^{3} \\
16.4^{5} \\
1.6\end{array}$ & $\begin{array}{l}53.2 \\
27.4^{3} \\
17.6^{5} \\
1.8\end{array}$ & $\begin{array}{l}48.3 \\
30.5^{4} \\
21.2^{6} \\
1.7\end{array}$ & $\begin{array}{l}47.1 \\
33.24 \\
19.76 \\
2.0\end{array}$ & $\begin{array}{l}54.5 \\
34.34 \\
10.96 \\
1.6\end{array}$ & $\begin{array}{l}56.7 \\
33.8^{4} \\
9.5^{6} \\
1.6\end{array}$ \\
\hline
\end{tabular}

* Means of 20 Friedreich's ataxia patients

+ Means of 10 Friedreich's ataxia patients

$\mp$ Means of 20 controls

$\S$ Means of 10 controls

1 Ultracentrifugation

2 Ultracentrifugation

3 Dual Precipitation

4 Ultracentrifugation

5 Dual Precipitation

6 Ultracentrifugation 
In 20 Friedreich's ataxia patients, serum cholesterol and triglyceride levels were predominately normal confirming the results of Podolsky et al, ${ }^{34}$ and Butterworth et $a l^{35}$ but contrary to the elevated serum cholesterol levels reported by Krongrad $e t ~ a l^{36}$ and elevated triglyceride levels reported by Badiu and Cherciulescu. ${ }^{37}$ Two of the Friedreich's ataxia patients did show increased cholesterol values but with no corresponding increase in triglyceride values; this may be due to one of the patients being diabetic and the other obese. The findings indicate that none of the patients have hypobetalipoproteinemia as, in hypobetalipoproteinemia, low LDL levels are associated with low serum cholesterol values. ${ }^{38}$

It has been shown that unusual fatty acid profiles can cause neurological disease as in Refsum's disease where large amounts of phytanic acid cause amongst other symptoms, ataxia and polyneuritis. ${ }^{9}$ Igarashi et al. ${ }^{10}$ have shown abnormal very long chain fatty acids in adrenoleucodystrophy, an X-linked hereditary neurological disorder particularly affecting cerebral white matter, adrenal cortex and testes in young boys. The neurological symptoms are often the only manifestations of this disease.

The fatty acid profiles in Friedreich's ataxia did not show any abnormalities; the percentages were not significantly different from those of similarly disabled controls and there were no unusual peaks, confirming the findings of Huang et $a l^{8}$ and Yao and Dyck. ${ }^{39}$ Serum fatty acids vary in neurological diseases ${ }^{40}$ so it was essential to compare groups of equal disability. It is possible that unnatural fatty acids such as trans-trans or trans-cis linoleic acid were present which cannot be discriminated by gas liquid chromatography, tut it does not seem likely that this would cause any adverse effects when adequate amounts of the essential fatty acids are present in the diet. ${ }^{41}$

Disorders with decreased serum low density lipoprotein (LDL) levels are known to be associated with ataxia. In abetalipoproteinemia the symptoms include ataxia neuropathy and cardiac disturbances associated with complete or almost complete absence of LDL. ${ }^{6}$ Mars et $a l^{4}$ have reported 13 members of a kindred with familial hypobetalipoproteinemia, some of whom showed symptoms of a progressive demyelinating disorder affecting the central nervous system. Badiu and Cherciulescu ${ }^{37}$ and more recently Wastiaux et al have reported low LDL levels in Friedreich's ataxia and other ataxic conditions. Our investigations of 29 Friedreich's ataxia patients revealed no values below the normal lower limits of Lindgren et $a l^{29}$ in fact, six patients had slightly elevated results. It is difficult to estimate the significance of the previous findings; Badiu and Cherciulescu have not published actual values whilst Wastiaux et al showed normal control values considerably above the quoted mean values for this radial immunodiffusion method. It is not stated whether the patients were fasted; if they were not, this may account for the discrepancies between the results. The increased levels of LDL shown by six Friedreich's ataxia patients and three controls, are at the upper limit of the normal range, but this may only be an indication of increased risk of developing coronary disease.

Only Huang et $a l^{8}$ have reported HDL abnormalities in Friedreich's ataxia. In their study of 11 patients they showed considerably reduced protein, slightly low cholesterol, elevated triglyceride levels and an overall low level of HDL in Friedreich's ataxia serum. Severe deficiency or absence of HDL in plasma is found in Tangier disease $^{6}$ but this rare condition bears little resemblance to Friedreich's ataxia. Careful attention was given to the HDL determinations in view of the striking findings of Huang et $a l^{8}$ and therefore each component of HDL was effectively measured twice. However, we were unable to substantiate any abnormal finding in HDL. Total levels of HDL in serum measured in 20 Friedreich's ataxia patients showed almost exactly the same range of values and average results as 20 controls. Quantitative estimations of the major components of HDL, cholesterol, phospholipid and protein in 20 Friedreich's ataxia patients did not differ significantly from 20 control values. The protein component of HDL2 and HDL3 examined by SDS gel electrophoresis and isoelectricfocusing showed no qualitative differences ketween the Friedreich's ataxia and control groups.

The group of patients examined by Huang et $a l^{8}$ show some differences from our own, three of his 11 Friedreich's ataxia cases are known to have abnormalities of glucose metabolism which may cause the lipoprotein pattern to change ${ }^{38}{ }^{42}$; abnormality of glucose tolerance has been reforted to cause an elevation in very low density lipoproteins and chylomicrons with a corresponding decrease of LDL and HDL. Of his remaining eight Friedreich's ataxia patients four out of five had elevated bilirubin levels; the other three patients were not measured. Hamel et $a l^{43}$ estimate that approximately $30 \%$ of Friedreich's ataxia patients have elevated serum bilirubin levels, but these values may represent the top end of the normal range, and therefore, may not 
be significant. ${ }^{44}$ High bilirubin levels found in obstructive jaundice, however, are associated with very low concentrations of $\mathrm{HDL}^{21}$ but whether there is any relationship between such abnormalities and the HDL levels in this group of 11 patients, is difficult to elucidate. Direct and indirect bilirubin levels have been measured in 25 of our Friedreich's ataxia patients and no elevated levels were found (unpublished observation). As an alternative hypothesis the results of Huang et al may be due to a preponderance of an abnormal gene causing a low level of HDL in a genetically fairly homogenous population. Such a population is found in French Canada where it has been suggested that the Friedreich's ataxia gene was present within a core of no more than 10 families, ${ }^{45}$ but the U.K. has a considerably more heterogeneous population.

The gross analysis of tissue lipids showed no qualitative abnormality. The cerebral white and grey matter, cerebellum, spinal cord and heart lipid extracts in the two Friedreich's ataxia patients compared to the control showed absolutely identical bands and intensity of banding on thin layer chromatography plates. The procedure is sufficiently quantitative for most purposes. ${ }^{26}$

Further studies of specific lipid types may elucidate abnormalities in other lipids which are present in considerably lower concentrations.

In conclusion, results from this study and comparisons with the findings of the other workers infer that there is no clear indication of a significant defect of major lipid and lipoprotein components in Friedreich's ataxia.

Thesc studies were supported by the Friedreich's Ataxia Group. The authors thank Dr B J Houghton, Chemical Pathologist of The London Hospital for his continued assistance and Dr Joan Slack and Mrs Nancy Noble of the Institute of Child Health, London, for their help and advice.

\section{References}

1 Blackwood W, Corsellis JAN. Greenfield's Neuropathology. London: Edward Arnold, 1976: 626-9.

2 Geoffroy G, Barbeau A, Breton G et al. Clinical description and roentgenologic evaluation of patients with Friedreich's ataxia. Can J Neurol Sci 1976; 3:279-86.

3 Brady RO. Sphingolipidoses and other Lipid metabolic disorders. In: Albers RW, Siegel GJ, Katzman R, Agranoff B, eds. Basic Neurochemistry. Boston: Little, Brown \& Co, 1976: 556-68.

4 Mars H, Lewis LA, Robertson AL, Sutkus A,
Williams GH Jr. Familial hypo- $\beta$-lipoproteinemia-a genetic disorder of lipid metabolism with nervous system involvement. Am J Med 1969; 46:886-900.

5 Aggerbeck LP, McMahon JP, Scanu AM. Hypobetalipoproteinemia: Clinical and biochemical description of a new kindred with 'Friedreich's Ataxia'. Neurology (Minneap) 1974; 24:1051-63.

6 Frederickson DS, Gotto AM, Levy RI. Familial lipoprotein deficiency. In: Stanbury JB, Wyngaarden JB, Frederickson DS, eds. The metabolic basis of inherited disease. New York: McGraw Hill, 1972: 493-530.

7 Wastiaux JP, Lamoureux G, Bouchard JP, Durivage A, Barbeau C, Barbeau A. HLA and complement typing in olivo-ponto-cerebellar atrophy. Can J Neurol Sci 1978; 5:75-82.

8 Huang YS, Nestruck AC, Barbeau A, Bouchard JP, Davignon J. Plasma lipids and lipoproteins in Friedreich's ataxia and familial spastic ataxiaEvidence for an abnormal composition of high density lipoproteins. Can J Neurol Sci 1978; 5:149-56.

9 Steinberg D. Phytanic acid storage disease: Refsum's syndrome. In: Stanbury JB, Wyngaarden JB, Frederickson DS, eds. The metabolic basis of inherited disease. New York: McGraw Hill, 1972: 833-53.

10 Igarashi M, Schaumberg HH, Powers J, Kishimoto Y, Kolondy E, Suzuki K. Fatty acid abnormality in adrenoleukodystrophy. $J$ Neurochem 1976; 26:851-60.

11 Robinson N. Chemical changes in the spinal cord in Friedreich's ataxia and motor neurone disease. J Neurol Neurosurg Psychiatry 1966; 31:330-3.

12 Zlatkis A, Zak B, Boyle AJ. New method for direct determination of serum cholesterol. J Clin Lab Med 1953; 41:486-92.

13 Eggstein M. Eine neue Bestimmung der Neuralfette im Blutserum und Gewebe II. Zuverlassigkeit de Methode, andere Neutralfettoestimmungen, Normalwerte fur Triglyceride and Glycerine im menschlichen Blut. Klin Wochenschr 1966; 44:267-73.

14 Folch J, Lees M, Sloan-Stanley GH. A simple method for the isolation and purification of total lipids from animal tissues. J Biol Chem 1957; 226:497-509.

15 Danon A, Heimberg M, Oates J. Enrichment of rat tissue lipids with fatty acids that are prostaglandin precursors. Biochim Biophys Acta 1975; 388:318-30.

16 Mancini G, Carbonaro AO, Heremans JS. Immunochemical quantitation of antigens by single radial diffusion. Immunochemistry 1965; 2:235-54.

17 Gros M, Jurman-Gros T. Electrophoretic separation of prestained serum lipoproteins on cellulose acetate, agarose gel and polyacrylamide. Clin Chim Acta 1973; 45:165-7. 
18 Laurell CB. Quantitative estimation of proteins by electrophoresis in agarose gel containing antibodies. Annals of Biochemistry 1966; 15:45-52.

19 Demacker PNM, Vos Janssen HE, Jansen AP, Van't Laar. Evaluation of the dual precipitation method by comparison with the ultracentrifugation method of measurement of lipoproteins in serum. Clin Chem 1977; 23:7, 1238-44.

20 Raheja RK, Charajit K, Singh A, Bhatia IS. New colourimetric method for the quantitative estimation of phospholipids without acid digestion. J Lipid Res 1973; 14:695-6.

21 Lindgren FT, Nichols AV. Structure and function of human serum lipoproteins. In: Putnam FW, ed. The Plasma Proteins. New York: Academic Press, 1960.

22 Lowry OH, Rosebrough NJ, Farr AL, Randall RJ. Protein measurement with the folin phenol reagent. J Biol Chem 1951; 193:265-75.

23 Pesce MA, Strande CS. A new micromethod for determination of protein in cerebrospinal fluid and urine. Clin Chem 1973; 19:1265-7.

24 Fehrnström H, Moberg F. SDS and conventional polyacrylamide gel electrophoresis with LKB 2117 Multiphor. Application Note 306, LKB Produkter AB, Bromma: Sweden, 1977.

25 Winter A, Ek K, Anderson VB. Analytical electrofocusing in thin layers of polyacrylamide gels. Application Note 250, LKB Produkter AB, Bromma: Sweden, 1977.

26 Suzuki K. Chemistry and metabolism of brain lipids. In: Albers RW, Siegel GJ, Katzman R, Agranoff B, eds. Basic Neurochemistry. Boston: Little, Brown \& Co, 1976: 308-28.

27 Baron DN. A short textbook of Chemical Pathology. London: English University Press, 1973: 65.

28 Slack J, Noble N, Meade TW, North WRS. Lipid and lipoprotein concentrations in 1604 men and women in working populations in north-west London. Br Med J 1977; 2:353-6.

29 Lindgren FT, Adamson GL, Jenson LC, Wood PD. Lipid and lipoprotein measurements in a normal adult American population. Lipids 1975; 10:850-756.

30 Foreman JR, Karlin JB, Eledstein C, Juhn DJ, Rubenstein AH, Scanu AM. Fractionation of human serum lipoproteins by single spin gradient ultracentrifugation: Quantification of apoproteins $\mathrm{B}$ and $\mathrm{A}-1$ and lipid components. J Lipid Research 1977; 18:759-67.
31 Eder HA, Roheim PS. Plasma lipoproteins and apolipoproteins. Ann NY Acad Sci 1976; 275: 169-79.

32 Jepson JB. Hartnup disease. In: Stanbury JB, Wyngaarden JB, Frederickson $\mathrm{DS}$, eds. The metabolic basis of inherited disease. New York: McGraw Hill, 1972: 1486-503.

33 Falk RE, Cederbaum SD, Blass JP, Gibson GE, Kark RAP, Carrel RE. Ketonic diet in the management of pyruvate dehydrogenase deficiency. Paediatrics 1976; 58:713-21.

34 Podolsky S, Pothier A, Krall LP. Association of diabetes mellitus and Friedreich's ataxia. Arch Int Med 1964; 114:533-7.

35 Butterworth RF, Shapcott D, Melancon S et al. Clinical laboratory findings in Friedreich's ataxia. Can J Neurol Sci 1976; 3:355-60.

36 Krongrad E, Joos HA. Friedreich's ataxia in childhood. Chest 1972; 61:644-8.

37 Badiu G, Cherciulescu F. A biochemical test for different diagnosis between acanthocytosis and spinocerebellar degenerations. Eur Neurol 1969; 2:315-7.

38 Ageta M, Yamasaki S, Nanbu S, Mae H. Characteristics of plasma lipids and lipoproteins in patients displaying abnormal glucose intolerance tests. In: Baba S, ed. Diabetes Mellitus in A sia. Amsterdam: Excerpta Medica, 1976: 154-63.

39 Yao JK, Dyck PJ. Lipid abnormalities in hereditary neuropathy. J Neurol Sci 1978; 36:225-36.

40 Kalofoutis A, Jullien G. A study of serum fatty acids in neurological diseases. Biochimie 1974; 56:623-4.

41 Privett OS, Phillips F, Shimasaki H, Nozawa MD, Nickell EC. Studies of effects of transfatty acids in the diet on lipid metabolism in essential fatty acid deficient rats. Am J Nutr 1977; 30: 1009-17.

42 Hamwi GJ, Garcia O, Kruger FA, Gwinup G, Cornwell DG. Hyperlipidemia in uncontrolled diabetes. Metabolism 1962; 11:850-62.

43 Hamel E, Bedard D, Laviolette F, Butterworth RF, Barbeau A. Familial hyperbilirubinemia in Friedreich's ataxia. Can J Neurol Sci 1978; 5:101-4.

44 Bailey A, Robinson D, Dawson AM. Does Gilbert's disease exist? Lancet 1977; 1:931-3.

45 Barbeau A, Le Siege M, Breton G, Coallier R, Bouchard JP. Friedreich's Ataxia: Preliminary results of some genealogical research. Can J Neurol Sci 1976; 3:303-6. 